\title{
Adolescents challenging discrimination: The benefits of a perspective-taking and action-planning intervention on self-efficacy
}

\author{
Lukas Wallrich $^{1}$ (1) | Sally B Palmer ${ }^{2}$ | Adam Rutland ${ }^{3}$
}

${ }^{1}$ Department of Psychology, London, Goldsmiths University of London, UK

${ }^{2}$ Graduate School of Education, Exeter, University of Exeter, UK

${ }^{3}$ Department of Psychology, Exeter, University of Exeter, UK

\section{Correspondence}

Lukas Wallrich, Department of Psychology, Goldsmiths, University of London, Whitehead Building, New Cross, London SE14 6NW, UK. Email: I.wallrich@gold.ac.uk

\begin{abstract}
Discrimination is widespread and often goes unchallenged because bystanders do not recognize the need to intervene or do not know how to intervene. This field experiment with adolescents $(N=639)$ tested a group discussion designed to increase perceived importance and self-efficacy around challenging general discrimination. The intervention, which involved perspective-taking and action-planning, was tested with delayed measures against active control conditions, namely sessions on self-disclosure and civic engagement. It led to greater self-efficacy, particularly among White participants. Please refer to the Supplementary Material section to find this article's Community and Social Impact Statement.
\end{abstract}

\section{KEYWORDS}

bystander intervention, discrimination, perspective-takingselfefficacy, youth work

\section{1 | INTRODUCTION}

Adolescents frequently experience and witness discrimination. This harms victims and reinforces bias (Yip \& Douglass, 2011). Encouraging peer bystanders to challenge discrimination can be one effective route to reducing discrimination (e.g., Hawkins, Pepler, \& Craig, 2001; Salmivalli, 2010). However, challenging discrimination requires different psychological mechanisms to general bullying as there are more psychological barriers to intervention in contexts where stigmatized groups are routinely victimized (Palmer \& Abbott, 2018). 
While subtle forms of discrimination can go unnoticed, many instances lack ambiguity. However, even when discrimination is noticed and evaluated negatively, this does not always lead to intervention (Aboud \& Miller, 2007). Therefore, our research focused on the steps that are required to move from evaluation to action, namely recognizing the importance of intervention and knowing how to intervene (Latané \& Darley, 1970). According to the theory of planned behaviour (Ajzen, 1991), self-efficacy is a critical component for enabling bystanders to turn intentions into intervention (Abbott, Cameron, \& Thompson, 2020; Ajzen, 1991; Bandura, 1997). This study examined whether peer group discussions about experiences of discrimination may (1) increase perceptions of importance around challenging discrimination and (2) increase self-efficacy of bystander intervention in these contexts. With that, we tested how these factors that have been identified as influences on bystander behaviour can be used to inform intervention design, and thus addressed the lack of focused intervention research (Abbott et al., 2020). We also examined whether adolescents' ethnicity influenced the effectiveness of the peer group discussions.

People who deem it important to challenge discrimination are more likely to do so. When adolescents perceived intergroup name-calling to be more severe, their intentions to intervene increased (Palmer, Rutland, \& Cameron, 2015). Likewise, European-American adolescents who viewed race-based jokes as less wrong expected peers to challenge less (Mulvey, Palmer, \& Abrams, 2016). Adolescents who experience discrimination-typically from minority backgrounds (Thijs, 2017)-are more likely to think challenging discrimination is important, because they are acutely aware of its impact. Awareness of the impact of discrimination might be increased among White majority-status adolescents by encouraging them to take the perspective of those who experience it; indeed, majority-status adolescents with good perspective-taking skills are more likely to challenge discrimination (Jenkins \& Nickerson, 2019).

Self-efficacy-individuals' belief in their competence to deal with a situation (Bandura, 1997)-is another predictor of bystander intervention. Those higher in self-efficacy defend victims of bullying more frequently (Abbott et al., 2020). Even when bystanders want to challenge bullying, if they feel unable to, they remain passive (Thornberg \& Jungert, 2013). The benefits of self-efficacy were established experimentally by Abbott et al. (2020) who had adolescents engage in a bully-victim-defender role-play. The role-play increased defender intentions, partially explained through increased self-efficacy. Therefore, it is likely that reactions to discrimination are predicted by self-efficacy. Specifically, young people may feel more able to confront discriminatory language if they have been given the opportunity to discuss potential reactions.

\section{2 | THE PRESENT STUDY}

This research was conducted with a UK volunteering program, the National Citizens Service (NCS). Introduced in 2011 to promote social cohesion and civic engagement, the NCS reaches 100,000 16-year-olds per year. Ethnic minorities and those eligible for free-school meals are represented in line with their population share among the participants (NCS Trust, 2020). Participants join a 4-week program with diverse youth from their local area that focuses on personal development and social action.

We asked participants to take part in one of three peer group discussions on Day 4 of the program, led by a facilitator. Those in the intervention condition discussed personal experiences of discrimination, engaged in perspective-taking, and considered possible reactions. We expected that discussing real experiences would highlight the importance of challenging discrimination, and thinking about possible reactions would promote self-efficacy. The second condition involved self-disclosure and active listening around experiences of social category affiliations. In the third condition, participants discussed social and environmental issues unrelated to discrimination.

The latter two conditions were active controls, designed to control for non-specific intervention effects. Including multiple controls supports the identification of underlying mechanisms (Karlsson \& Bergmark, 2015). The selfdisclosure condition allowed us to test whether effects could be attributed to our intervention design (focused on perspective-taking and action planning), or merely to facilitated self-disclosure concerning experiences of 
discrimination. The civic engagement condition would reveal the total intervention effect compared to a baseline of unrelated discussion.

We anticipated that intervention participants would deem it more important to confront discriminatory language, and feel greater self-efficacy, compared to both control conditions. Additionally, changes in perceived importance would be greater for White participants, given that they would gain more insight through perspective-taking compared to participants from minority-ethnic backgrounds, who might be more likely to have an existing understanding of the impacts of discrimination.

\section{3 | METHODS}

\section{1 | Design and procedure}

Groups of approximately 10 participants were randomly allocated to one of three 30-min discussions (Table 1). Full facilitator instructions are available with the analysis code (https://osf.io/xvwqf/). Outcome measures were collected after 3 weeks, at the end of the programme, in order to measure changes in attitudes rather than fleeting reactions to the intervention. Participants and facilitators were blinded to hypotheses.

One hundred and seventy three facilitators responded to a feedback survey including a manipulation check. Overall, most implemented the sessions as instructed, with no significant differences between conditions. Participants' level of engagement was reportedly high across all conditions. Therefore, our results are likely due to the planned activities rather than variations in implementation.

\section{2 | Participants}

Our partner asked 871 participants from 131 teams who had taken part in the experiment to complete their evaluation survey, which included our measures. Six hundred and thirty nine (73.4\%) responded to our measures, with no significant differences between conditions.

Due to a split survey design, ethnicity was only requested from a random subgroup. Among those $(N=276)$, 103 were White and 173 were from a minority-ethnic background (mostly South Asian, African and Caribbean British), including 13 from a mixed White and minority-ethnic background. These participants were in ethnically diverse teams, with a median normalised Teachman's index of .81 (Solanas, Selvam, Navarro, \& Leiva, 2012). ${ }^{1}$ Below,

TABLE 1 Overview of the conditions

\begin{tabular}{|c|c|}
\hline Condition & Activity \\
\hline $\begin{array}{l}\text { 1. Perspective-taking and action- } \\
\text { planning }(N=235)\end{array}$ & $\begin{array}{l}\text { Participants briefly write about an experience with a negative label. They } \\
\text { anonymously exchange the papers and take turns reading out the experiences } \\
\text { as if they were their own. All are asked to imagine and express what that } \\
\text { experience would feel like. Then they discuss possible reactions. }\end{array}$ \\
\hline $\begin{array}{l}\text { 2. Self-disclosure and active } \\
\text { listening }(N=166)\end{array}$ & $\begin{array}{l}\text { Participants reflect on labels that others have attached to them. They select a } \\
\text { negative and positive label. In pairs, they share these experiences, and listen } \\
\text { actively. }\end{array}$ \\
\hline 3. Civic engagement $(N=238)$ & $\begin{array}{l}\text { Participants discuss matters that concern young people (e.g., climate change). } \\
\text { They create ideas for action, and read inspirational stories (e.g., about Greta } \\
\text { Thunberg). }\end{array}$ \\
\hline
\end{tabular}


we present analyses for the full sample of 639 participants, followed by supplementary analyses for the subset that reported their ethnicity $(N=276)$.

\section{3 | Measures}

Importance. Participants were asked, "In a team, how important is it to point out (either publicly or privately) if others use language that may be offensive to members of certain backgrounds or lifestyles?" from $1=$ not at all important to $5=$ very important.

Self-efficacy. Participants were asked, "In a team, how comfortable would you feel to point out (either publicly or privately) if others use language that may be offensive to members of certain backgrounds or lifestyles?", from $1=$ not at all comfortable to $5=$ very comfortable.

\subsection{Analytic approach}

We estimated mixed-effects models, including random intercepts to account for shared variance within teams, using the Ime4 package in R (Bates, Mächler, Bolker, \& Walker, 2015).

\section{4 | RESULTS}

Table 2 shows descriptives by condition. Importance did not differ across conditions, $F(2,87)=0.88, p=.42$. There were significant differences for self-efficacy, $F(2,636)=4.73, p=.009$. Pairwise comparisons showed that the intervention led to marginally higher self-efficacy than the self-disclosure condition, $d=.23,95 \% \mathrm{Cl}[.03, .43], p=.056$, and significantly higher self-efficacy than the civic engagement condition, $d=.27,95 \% \mathrm{Cl}[.09, .45], p=.021$ (Figure 1). ${ }^{2}$

\section{1 | Moderation by participants' ethnicity}

We expected a greater change in importance and self-efficacy for White participants. Observed means followed that pattern (Table 3). As ethnicity was only available for some participants, statistical tests had reduced power. Consequently, omnibus tests suggested that ethnicity did not moderate importance, $F(2,244)=1.96, p=.14$ or self-efficacy, $F(2,270)=1.05, p=.35$. However, when testing intervention effects for White and minority-ethnic participants separately, analyses showed significant changes only for White participants. For importance, the intervention had a large, marginally significant, effect on White participants, $d=.60,95 \% \mathrm{Cl}[0.16,1.04], p=.057$, and no significant effect on minority-ethnic participants, $d=.05,95 \% \mathrm{Cl}[-.36, .41], p=.94$. The intervention also led to a large increase in self-efficacy for White participants, $d=.47,95 \% \mathrm{Cl}[.06, .93], p=.035$, but not for minority-ethnic participants, $d=.01,95 \% \mathrm{Cl}[-.38, .39], p=.99$.

TABLE 2 Means and SDs by condition

\begin{tabular}{llll} 
Condition & $N$ & Importance & Self-efficacy \\
\hline 1. Perspective-taking and action planning & 235 & $3.92(1.13)$ & $3.75(0.99)$ \\
2. Self-disclosure and active listening & 166 & $3.78(1.02)$ & $3.52(1.04)$ \\
3. Civic engagement discussion & 238 & $3.82(0.89)$ & $3.49(0.98)$ \\
\hline
\end{tabular}


FIGURE 1 Self-efficacy for speaking up against offensive language by condition

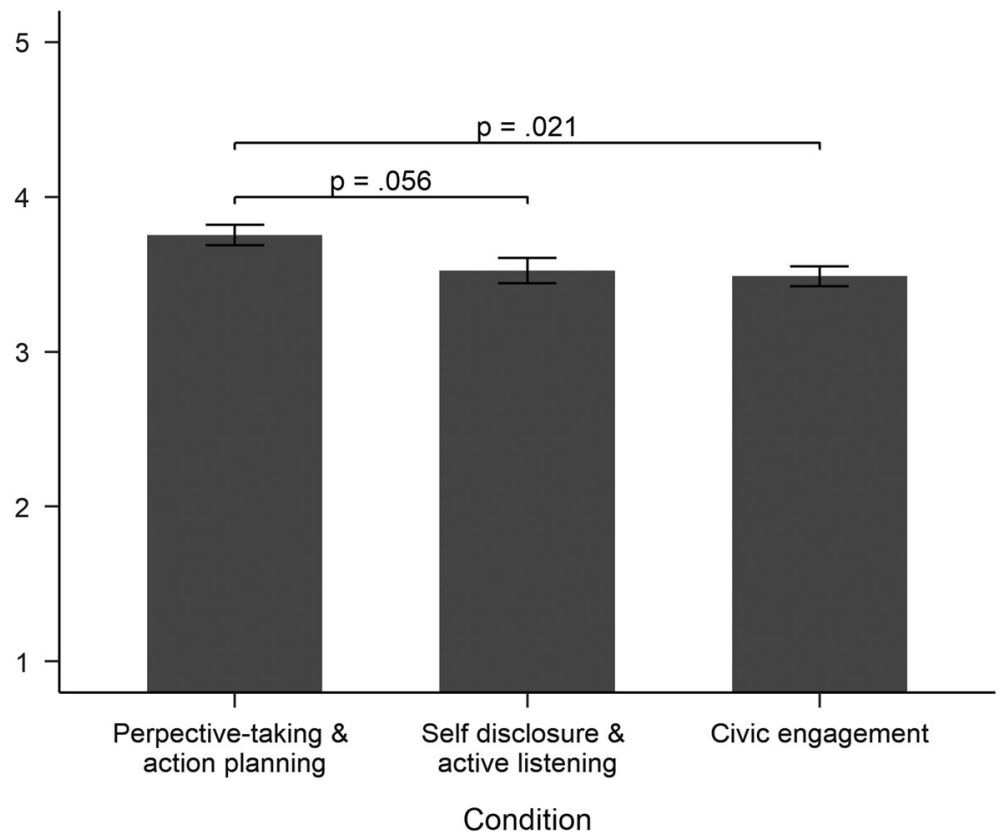

TAB LE 3 Means and SDs by condition and participants' ethnicity

\begin{tabular}{|c|c|c|c|c|c|c|}
\hline \multirow[b]{2}{*}{ Condition } & \multicolumn{3}{|c|}{ White participants } & \multicolumn{3}{|c|}{ Minority-ethnic participants } \\
\hline & $N$ & Importance & Self-efficacy & $\mathrm{N}$ & Importance & Self-efficacy \\
\hline 1. Perspective-taking and action planning & 48 & $4.21(0.92)$ & $3.92(0.9)$ & 64 & $3.83(1.23)$ & $3.56(1.11)$ \\
\hline 2. Self-disclosure and active listening & 21 & $4.19(0.98)$ & $3.71(1.01)$ & 63 & $3.71(1.02)$ & $3.57(0.96)$ \\
\hline 3. Civic engagement discussion & 40 & $3.72(0.78)$ & $3.52(0.75)$ & 40 & $3.78(0.92)$ & $3.55(0.85)$ \\
\hline
\end{tabular}

\section{5 | DISCUSSION}

Extending recent research (Abbott et al., 2020), we showed that group-discussions focused on perspective-taking and action-planning bolster self-efficacy around challenging discrimination, particularly for White adolescents. Additionally, the intervention marginally increased White adolescents' perception of the importance of intervening as compared to participants in the control condition (no consideration of discrimination). The inclusion of a second control condition that focused on self-disclosure of experiences of discrimination allowed us to assess whether the effects are attributable to more specific features of our intervention. While our results on this are only marginally significant, they suggest that perspective-taking and action planning had an incremental effect on self-efficacy, but not on perceived importance.

The differences between ethnic majority and minority participants are in line with those observed in the intergroup contact literature, where contact consistently has a greater effect on majority- than on minority-status participants (Tropp \& Pettigrew, 2005). We expect that this was the case here because White participants gained more novel insights in the course of the intervention, compared to minority-ethnic participants who have greater familiarity with the realities of discrimination and exclusion. The fact that our intervention affected self-efficacy more than perceived importance might be due to the context. Inclusiveness and non-discrimination are key values of the NCS, 
so that positive interactions with members of different ethnic groups take place throughout the program (Reimer, Love, Wölfer, \& Hewstone, 2021).

Our results are conservatively estimated, against active controls and after a cooldown period of 3 weeks. Furthermore, the field setting highlights the application potential in various educational contexts. However, we are unable to clearly identify causal mechanisms, and found no evidence for the effectiveness of our intervention among minority-ethnic participants. Additionally, we were limited in the amount of data we could collect, having to rely on a single timepoint with single-item measures and no manipulation checks. Future research should consider whether interventions effects last over a longer period, and whether the intervention shapes behaviour as well as intentions. It should also disentangle perspective-taking and action-planning to test whether the intervention works in less diverse settings, and explore how minority-ethnic youth can be supported to challenge discriminatory language. Additionally, an exploration of the effectiveness of this type of intervention in tackling different types of discrimination (e.g., interpersonal versus intergroup) would be worthwhile. Finally, a qualitative exploration of the instances of discrimination that adolescents share could add further insights, potentially also explaining the gap between ethnic groups.

In conclusion, the current study shows how a 30-min group discussion of discrimination experiences, focused on perspective-taking and action-planning, could prompt higher self-efficacy for dealing with offensive discriminatory language, 3 weeks later, particularly among White adolescents. Given that self-efficacy is a known precursor to challenging general aggression, our findings suggest that self-efficacy interventions focused on challenging discrimination specifically, which can be implemented cheaply and easily, could facilitate bystander intervention against discrimination in adolescence.

\section{CONFLICT OF INTEREST}

There are no conflicts of interests to report; no external funding was used for the research.

\section{DATA AVAILABILITY STATEMENT}

Materials and replication code are available on the OSF: https://osf.io/xvwqf/. The dataset is available on request from the first author.

\section{ETHICS STATEMENT}

The research followed the ethical guidelines of the British Psychological Society; it was approved by the Goldsmiths, University of London, Psychology Departmental Research Ethics Committee.

\section{ORCID}

Lukas Wallrich (D) https://orcid.org/0000-0003-2121-5177

\section{ENDNOTES}

${ }^{1}$ Normalised Teachman indices range from 0 (all minority or majority-status) to 1 (equal numbers from minority- and majority-status categories). An index of .88 (similar to the observed median) would describe a team consisting of seven participants from one group and three participants from another group.

2 To enhance transparency, $p$-values for post hoc comparisons are reported after Holm-Bonferroni adjustment for three comparisons, while confidence intervals are reported without adjustment.

\section{REFERENCES}

Abbott, N., Cameron, L., \& Thompson, J. (2020). Evaluating the impact of a defender role-play intervention on adolescent's defender intentions and responses towards name-calling. School Psychology International, 41, 154-169. https://doi.org/ 10.1177/0143034319893410

Aboud, F., \& Miller, L. (2007). Promoting peer intervention in name-calling. South Africa Journal of Psychology, 37(4), 803819. https://doi.org/10.1177/008124630703700409 
Ajzen, I. (1991). The theory of planned behavior. Organizational Behavior and Human Decision Processes, 50(2), $179-211$. https://doi.org/10.1016/0749-5978(91)90020-T

Bandura, A. (1997). Self-efficacy: The exercise of control. New York, NY: Freeman.

Bates, D., Mächler, M., Bolker, B., \& Walker, S. (2015). Fitting linear mixed-effects models using Ime4. Journal of Statistical Software, 67(1), 1-48. https://doi.org/10.18637/jss.v067.i01

Hawkins, D. L., Pepler, D. J., \& Craig, W. M. (2001). Naturalistic observations of peer interventions in bullying. Social Development, 10(4), 512-527. https://doi.org/10.1111/1467-9507.00178

Jenkins, L. N., \& Nickerson, A. B. (2019). Bystander intervention in bullying: Role of social skills and gender. The Journal of Early Adolescence, 39(2), 141-166. https://doi.org/10.1177/0272431617735652

Karlsson, P., \& Bergmark, A. (2015). Compared with what? An analysis of control-group types in Cochrane and Campbell reviews of psychosocial treatment efficacy with substance use disorders. Addiction, 110(3), 420-428. https://doi.org/ 10.1111/add.12799

Latané, B., \& Darley, J. M. (1970). The unresponsive bystander: Why doesn't he help?. New York, NY: Appleton-Century Crofts.

Mulvey, K. L., Palmer, S. B., \& Abrams, D. (2016). Race-based humor and peer group dynamics in adolescence: Bystander intervention and social exclusion. Child Development, 87, 1379-1391. https://doi.org/10.1111/cdev.12600

NCS Trust. (2020). National citizen service annual report and accounts 2018/2019. Retrieved from https://www.gov.uk/ government/publications/national-citizen-service-annual-report-and-accounts-20182019

Palmer, S. B., \& Abbott, N. (2018). Bystander responses to bias-based bullying in schools: A developmental intergroup approach. Child Development Perspectives, 12(1), 39-44. https://doi.org/10.1111/cdep.12253

Palmer, S. B., Rutland, A., \& Cameron, L. (2015). The development of bystander intentions in an intergroup context: The role of perceived severity, ingroup norms, and social-moral reasoning. British Journal of Developmental Psychology, 33(4), 419-433. https://doi.org/10.1111/bjdp.12092

Reimer, N. K., Love, A., Wölfer, R., \& Hewstone, M. (2021). Building social cohesion through intergroup contact: Evaluation of a large-scale intervention to improve intergroup relations among adolescents. Journal of Youth and Adolescence. https://link.springer.com/article/10.1007/s10964-021-01400-8\#citeas

Salmivalli, C. (2010). Bullying and the peer group: A review. Aggression and Violent Behavior, 15(2), 112-120. https://doi.org/ 10.1016/j.avb.2009.08.007

Solanas, A., Selvam, R. M., Navarro, J., \& Leiva, D. (2012). Some common indices of group diversity: Upper boundaries. Psychological Reports, 111(3), 777-796. https://doi.org/10.2466/01.09.21.PR0.111.6.777-796

Thijs, J. (2017). Children's evaluations of interethnic exclusion: The effects of ethnic boundaries, respondent ethnicity, and majority in-group bias. Journal of Experimental Child Psychology, 158, 46-63. https://doi.org/10.1016/j.jecp.2017.01.005

Thornberg, R., \& Jungert, T. (2013). Bystander behavior in bullying situations: Basic moral sensitivity, moral disengagement and defender self-efficacy. Journal of Adolescence, 36(3), 475-483. https://doi.org/10.1016/j.adolescence.2013.02.003

Tropp, L. R., \& Pettigrew, T. F. (2005). Relationships between intergroup contact and prejudice among minority and majority status groups. Psychological Science, 16(12), 951-957. https://doi.org/10.1111/j.1467-9280.2005.01643.x

Yip, T., \& Douglass, S. (2011). Ethnic/racial identity and peer relationships across elementary, middle, and high schools. In X. Chen \& K. H. Rubin (Eds.), Socioemotional development in cultural context (pp. 186-207). New York, NY: Guilford.

\section{SUPPORTING INFORMATION}

Additional supporting information may be found online in the Supporting Information section at the end of this article.

How to cite this article: Wallrich L, Palmer SB, Rutland A. Adolescents challenging discrimination: The benefits of a perspective-taking and action-planning intervention on self-efficacy. J Community Appl Soc Psychol. 2021;1-7. https://doi.org/10.1002/casp.2530 